\title{
Laryngeal $\mathrm{T}$ regulatory cells in the setting of smoking and reflux
}

\author{
Marie E. Jetté, Ph.D., \\ Department of Otolaryngology, School of Medicine, University of Colorado Denver, Anschutz \\ Medical Campus, Aurora, CO, USA \\ Christine M. Seroogy, M.D., and \\ Department of Pediatrics, School of Medicine and Public Health, University of Wisconsin, \\ Madison, WI, USA \\ Susan L. Thibeault, Ph.D. ${ }^{1}$ \\ Division of Otolaryngology-Head and Neck Surgery, Department of Surgery, School of Medicine \\ and Public Health, University of Wisconsin, Madison, WI, USA
}

\begin{abstract}
Objective-The larynx is a mucosal organ rich in lymphatic tissue that is regularly exposed to a multitude of inhaled, ingested, and refluxed microorganisms and irritants. The first line of mucosal immune defense is the barrier, including resident immune cells. T regulatory (Treg) cells are a specialized subset of CD4+ T cells that suppress or dampen immune responses to prevent damaging immunopathology. As Treg cells have been shown to preferentially accumulate at sites of infection and Treg responses may contribute to persistence of infection by impairing antibacterial immunity, we sought to quantify these cells in laryngeal tissue exposed to smoking and reflux.
\end{abstract}

\section{Study Design-Cross-sectional study}

Methods-Using an epigenetic assay, we quantified Treg and $\mathrm{T}$ cells and calculated the ratio of Treg to T cells (i.e., cellular ratio of immune tolerance or "ImmunoCRIT") in disease-free laryngeal biopsies representing four inflammatory states: (1) tobacco-exposed tissue; (2) refluxate and tobacco-exposed tissue; (3) refluxate-exposed tissue; and (4) unexposed tissue.

Results-There was epigenetic evidence of Treg cells in all tissues, and we found no differences in Treg cell frequency relative to smoking and reflux in laryngeal tissue collected from 42 nontreatment-seeking participants. There was a decrease in total $\mathrm{T}$ cell frequency and an increase in ImmunoCRIT values in smokers regardless of reflux status.

Conclusion-In this study, laryngeal tissue from smokers show decreased overall $\mathrm{T}$ cells and increased ImmunoCRIT values. Our findings indicate that laryngeal inflammation is not directly

\footnotetext{
${ }^{1}$ Address correspondence to: Susan L. Thibeault, 5107 Wisconsin Institutes for Medical Research, 1111 Highland Avenue, Madison, WI 53705, 608-263-0121, thibeault@ surgery.wisc.edu.

This work was completed at the University of Wisconsin-Madison.

The authors report no financial or non-financial conflicts of interest.

This manuscript was presented at the Combined Otolaryngology Spring Meetings in Chicago, Illinois on May 19, 2016.

Level of Evidence: NA
} 
mediated by loss of Treg cells in response to smoking and this environmental exposure in modulating laryngeal immune homeostasis. More studies are indicated to explore Treg cell dysfunction in the pathophysiology of laryngeal disease.

\section{Keywords}

larynx; T regulatory cell; vocal fold; mucosal immunity

\section{Introduction}

The larynx represents a major site of exposure to inhaled, ingested, and refluxed microorganisms and irritants. To address these challenges, the mucosal larynx is rich in lymphoid tissue localized to the laryngeal surface of the epiglottis and the false vocal folds ${ }^{1-3}$. Larynx-associated lymphoid tissue (LALT) is characterized by the presence of reactive germinal centers containing macrophages, dendritic cells and T lymphocytes, though its role in immune defense remains unknown ${ }^{2}$.

The healthy adaptive immune response balances the activity of effector and suppressor cells (Figure 1). Cluster of differentiation 3 (CD3) protein complex is expressed on all $\mathrm{T}$ cell lineages. Most CD3 + T lymphocytes have differentiated, or have the ability to differentiate into effector $\mathrm{T}$ cells important for pathogen eradication or cellular destruction. In contrast, $\mathrm{T}$ regulatory (Treg) cells, defined as CD4+CD25+forkhead box (Fox)P3+, are CD3+ T cell subset that act by suppressing or dampening heightened immune responses thereby preventing the incidence of damaging immunopathology. Treg cells are also implicated in chronic infections, as their role in weakening the immune response can result in persistence of an infectious organism or agent ${ }^{4}$. Treg cells secrete anti-inflammatory cytokines, including IL-10 and TGF- $\beta$ and express the inhibitory co-stimulatory protein, cytotoxic Tlymphocyte 4 (CTLA-4) and they can be induced from naïve $\mathrm{T}$ effector cells in the periphery or develop naturally in the thymus. Induced Treg cells commonly arise at sites of constant exposure to foreign antigens in locations where there is contact with the external environment (e.g., mucosal surfaces) ${ }^{5}$. Since Treg cells have been shown to be involved in both the control of immunopathology and the persistence of chronic infections, we assessed differences in laryngeal tissue $\mathrm{T}$ cell and Treg cell frequencies relative to two etiologic factors implicated in laryngeal inflammation - smoking and reflux - hypothesizing that there would be elevated Treg cells in exposed tissue.

To specifically quantify tissue $T$ cells and Treg cells, we used a validated epigenetic approach. Since activated effector T cells can transiently express Foxp3 protein without demethylating critical Treg promoter regions known to maintain the Treg cell phenotype, differences in Treg-specific demethylated region (TSDR) using bisulfite sequencing and quantitative polymerase chain reaction (qPCR) was used to quantify total CD3+ T cells and Treg cells. The ratio of Treg cells to all CD3+ T cells has been referred to as the "cellular ratio of immune tolerance" or "ImmunoCRIT", an important determinant of immune tolerance ${ }^{6}$. In the cancer literature, benign pathology demonstrates a significantly decreased median ImmunoCRIT values compared with tumors of increasing aggressiveness ${ }^{6,7}$. We 
therefore hypothesized that laryngeal tissue exposed to smoking and reflux would yield increased ImmunoCRIT values relative to unexposed tissue.

\section{Materials and Methods}

\section{Participant Selection}

Participants aged 21-65 years were recruited with newspaper and email advertisements and signs in the clinic and around the University of Wisconsin-Madison. Participants underwent videolaryngostroboscopic examination and 24-hour multichannel intraluminal impedance with $\mathrm{pH}$ monitoring, with each procedure performed on separate dates. The protocol was approved by the Institutional Review Board of University of Wisconsin-Madison and informed consent was obtained from all participants. Inclusion and exclusion criteria for each participant is outlined in detail in Jette et al. ${ }^{8}$. Briefly, participants were excluded from the study if they had a recent history of laryngeal surgery or disease and/or substance or alcohol abuse. Additionally, they were excluded for taking any medications associated with reflux treatment. Nonsmokers had not smoked during the previous year, whereas smokers were designated based on consumption of a minimum of 5 cigarettes $/ 5 \mathrm{~g}$ of tobacco per day for the duration of one or more years, thereby distinguishing them from light smokers ${ }^{9,10}$.

\section{Reflux Diagnosis}

Participants underwent 24-hour multichannel intraluminal impedance monitoring with $\mathrm{pH}$ probe for objective reflux diagnosis. They were designated into three cohorts - Normal, Laryngopharyngeal Reflux (LPR), and Gastroesophageal Reflux (GERD) - based on criteria outlined in Jette et al. ${ }^{8}$ as summarized in Table 1.

\section{Sample Collection}

An Olympus ENF-T3 flexible fiberoptic laryngoscope with biopsy forceps passed through a biopsy channel was used following topical anesthesia with $4 \%$ lidocaine and tissue was sampled from the false vocal cords. In all cases, sampling was completed aseptically. Tissue biopsies were snap frozen within seconds of retrieval and stored at $-80^{\circ} \mathrm{C}$ prior to processing for molecular analysis.

\section{Genomic DNA Isolation}

DNA was extracted with the EpiCenter MasterPure Complete DNA and RNA Purification Kit (Illumina, Madison, WI) with modifications to the manufacturer's protocol as described in a paper previously published by our research group ${ }^{11}$. In brief, silica beads and proteinase $\mathrm{K}$ were used to lyse and homogenize tissue with regular vortexing. DNA was resuspended in TE, quantified using a spectrophotometer (NanoDrop, Thermo Scientific, Wilmington, DE) and stored at $-20^{\circ} \mathrm{C}$ until use.

\section{Bisulfite-conversion, Bisulfite Sequencing and qPCR}

Genomic DNA was sent to Epiontis (Berlin, Germany) for epigenetic analysis. Bisulfite conversion of genomic DNA, bisulfite sequencing of FOXP3,CD3 $\gamma$ and $C D 3 \delta$ regions, and $G A P D H$, and qPCR was performed as described elsewhere. ${ }^{12}$ Sequencing analysis was 
completed as previously described in Barth et al. ${ }^{7}$ In brief, Treg cell frequency was determined by calculating the percentage of TSDR demethylation (Treg cell epigenetic signature) divided by GAPDH demethylation as the denominator within the genomic DNA sample. Overall T cell frequency was determined as the percentage of demethylated $C D 3 \gamma$ and $C D 3 \delta$ intergenic region (CD3) divided by the GAPDH demethylation as the denominator. ImmunoCRIT is calculated as a ratio of percent TSDR demethylation divided by the percent of $C D 3$ demethylation as denominator within each sample.

\section{Statistical Analysis}

Data including T cell \%, Treg \%, and ImmunoCRIT were analyzed using general linear modeling including the main effects of smoking and reflux using $\mathrm{R}^{13}$ and t-tests in Prism (GraphPad, La Jolla, CA) to assess differences between smokers and nonsmokers.

\section{Results}

\section{Participant and Sample Characteristics}

Clinical and demographic characteristics of the participants are outlined in Table 2. Genomic material extracted from false vocal fold biopsies of 43 participants yielded sufficient concentrations of DNA ( $>2.5 \mu \mathrm{g}$ ) for epigenetic analysis and were sent to Epiontis for analysis. Of these, 42 passed quality control for Treg and $\mathrm{T}$ cell epigenetic analysis.

\section{Laryngeal Tissue Treg cell Frequency, T cell Frequency, and ImmunoCRIT Values}

Treg cell frequency $(\%)$ varied from $0.4-5.2 \%$ (mean $=1.6 \%$ ) and $\mathrm{T}$ cell $\%$ varied from 3.4 $53.1 \%($ mean $=22.2 \%)$ across all samples. ImmunoCRIT values ranged from 2.7-30.7. A general linear model including the main effects of reflux and smoking demonstrated no differences in the frequency (\%) of Treg cells attributed to these characteristics. The frequency (\%) of total CD3+ T cells was decreased in smokers (Figure 2), and unaffected by other participant characteristics including sex and age. ImmunoCRIT values were increased in smokers. See Table 3 for detailed results of linear regression analysis.

\section{Discussion}

It has been hypothesized that the larynx is an important organ for immunological decisionmaking in the airway ${ }^{14}$, as it represents a major site of exposure to pathogens and irritants. The present study complements the existing larynx immunology literature by comparing Treg cells in human tissue that has had variable exposure to refluxate and cigarette smoke. While there was epigenetic evidence of Treg cells in all tissues analyzed, our analysis revealed no differences in Treg cell frequency relative to smoking or reflux in laryngeal tissue analyzed from 42 non-treatment seeking participants. We did, however, document a decrease in overall (CD3+) T cells and an increase in ImmunoCRIT values in smokers regardless of reflux status.

$\mathrm{T}$ cells are one component of the complex adaptive immune system that contribute to the detection and destruction of pathogens. The CD3 protein complex is a defining feature of the $\mathrm{T}$ cell lineage and it is present at all stages of $\mathrm{T}$ cell development. The major $\mathrm{T}$ cell 
population that protects the host from invading pathogenic bacteria is referred to as CD4+ T cells. There are many established subsets of effector CD4+ T cells including, among others, Th1, Th2, and Th17 cells, all of which express a variety of cell surface markers. Th1 cells are produced in response to antigens derived from intracellular bacteria and viruses, Th2 cells are generated in the presence of parasitic helminthes, and Th17 effector cells develop in response to extracellular bacteria and fungi. Treg cells act to regulate the function of those potentially destructive pro-inflammatory effector $\mathrm{T}$ cells, thereby suppressing any faulty activation of the immune system that could lead to damage of the body's own tissues ${ }^{15}$. Treg cells are CD4+ and express constitutive CD25 (IL-2Ra) and the transcription factor FoxP3. FoxP3 plays an important role in the maintenance, survival, and suppressive function of Treg cells such that mice deficient in this transcription factor rapidly develop fatal autoimmune disease $^{16}$. Treg cells secrete anti-inflammatory cytokines, including IL-10 and TGF- $\beta$ and express the inhibitory co-stimulatory receptor cytotoxic T-lymphocyte 4 (CTLA-4) and they can be induced from naïve $\mathrm{T}$ effector cells in the periphery or arise naturally from the thymus. While CD25 is upregulated in naïve T cells following stimulation by antigens and subsequent differentiation into Treg cells, it is also expressed by CD8+ T cells ${ }^{17}$ and $\mathrm{B}$ cells ${ }^{18}$. FoxP3 is necessary to program cells for Treg function ${ }^{19}$. Treg cells commonly accumulate at sites of constant exposure to foreign antigens in locations where there is contact with the external environment (e.g., mucosal surfaces) ${ }^{5}$.

Both animal and human studies have revealed LALT, a type of mucosa-associated lymphoid tissue (MALT) specific to the larynx ${ }^{20-24}$, particularly in the region of the laryngeal surface of the epiglottis and false vocal folds, suggesting an immunologic role for the larynx.

Dendritic cells, $\mathrm{T}$ cells, and macrophages have been detected in histologic sections procured from human fetal laryngeal tissue ${ }^{25}$. In pig $^{26}$, there is histologic evidence of CD3+ T cells distributed diffusely both within and beneath the epithelium, CD4+ and CD8+ T cells in the epithelium and subglottis, and scarce double-positive CD4+CD8+ effector T cells in the laryngeal mucosa.

In our study, smokers had reduced T cell frequencies compared to nonsmokers. Analysis of circulating T lymphocytes in peripheral blood mononuclear cells of patients with head and neck cancer and normal controls using flow cytometry revealed decreased $\mathrm{T}$ cells in patients with cancer even in patients with no evidence of disease ${ }^{27}$. The authors suggest that lymphocyte homeostasis fails to normalize following treatment; however, the majority of the patients included in the study were smokers or former smokers, therefore another potential interpretation is that continued smoking contributed to decreased T cells. Support for our finding of decreased overall $\mathrm{T}$ cells in smokers also comes from animal studies that demonstrate immunosuppression in animals exposed to nicotine ${ }^{28,29}$. In contrast to our study results, Rees et al. ${ }^{30}$ found increased CD4+ T cells in laryngeal tissue of smokers. The discrepancy in results may be related to multiple study design factors including different sample sizes of smokers and nonsmokers and experimental techniques. Though our sample sizes were smaller, we employed a precise, quantitative epigenetic assay as opposed to semiquantitative immunohistochemistry as demonstrated in Rees et $\mathrm{al}^{30}$.

In addition to decreased $\mathrm{T}$ cells in smokers, we also found increased ImmunoCRIT values, a measure of the equilibrium between Tregs and total $\mathrm{T}$ cells, in these individuals compared to 
nonsmokers. Mean ImmunoCRIT values of nonsmokers in this study fall within the range of median values for healthy tissue as established by Turbachova et al. ${ }^{6}$. These authors also demonstrated elevated ImmunoCRIT values in cancerous relative to benign tissues and suggested that a shift toward increased ImmunoCRIT is a prerequisite to tumor growth in all tissues regardless of total $\mathrm{T}$ cell counts ${ }^{6}$. Research linking peripheral blood ImmunoCRIT values and cancer development found that both smoking and sex influenced ImmunoCRIT ${ }^{7}$. In the context of these findings, our results suggest that cigarette smoke may play a role in modulating the immune system toward tolerance, thereby reducing an effector response and creating an environment for tumor cell proliferation.

Contrary to what we predicted, reflux was not associated with alterations in Treg or T cell frequencies, or associated ImmunoCRIT. Inflammatory reactions in the airway have been demonstrated to be induced by components of gastric reflux such as hydrochloric acid $(\mathrm{HCl})^{31,32}$ and a previous study of tissue collected from patients with LPR demonstrated increased CD8+ (i.e., cytotoxic) T cell counts ${ }^{33}$; however, there is no evidence from our study that the potential inflammatory effects of reflux are mediated by Treg cells in local tissue. We therefore posit that the pathophysiology of laryngeal symptoms attributed to reflux disease such as hoarseness and throat clearing may not involve immunomodulation. Given their presence in laryngeal tissue, mechanistic studies of Treg cell function in the larynx warrant further investigation.

While we found evidence of laryngeal Treg cells in our study, we cannot know the function of these cells at the time that the biopsies were taken based on epigenetic analysis. For example, there is a subset of Treg cells that have been shown to display proinflammatory function in spite of exhibiting hallmark Treg characteristics ${ }^{34}$. Our interpretations of this study are also limited by confounding factors that are inherent to human clinical research. Elevated body mass index, for example, is associated with increased CD4+ T cells, particularly Tregs ${ }^{35}$. While medications targeting inflammation were included in the exclusionary criteria, we did not control for diagnoses of systemic inflammatory conditions or immunosuppression in our cohort, both of which may have skewed results.

\section{Conclusion}

An investigation of laryngeal tissue resulted in detecting both Treg cells and T cells with no differences relative to smoking and reflux in the frequency of Treg cells. However, the ratio of Treg cells to T cells, or ImmunoCRIT, in laryngeal tissues was significantly higher in smokers. Overall our findings suggest an imbalance between Treg cells and total T cells in the laryngeal tissue of smokers, irrespective of laryngeal inflammation.

\section{Acknowledgments}

Funding: NIDCD R01 DC009600, NIDCD T32 DC009401

This research was supported by funding from the National Institutes of Health/National Institute of Deafness and other Communication Disorders R01DC009600 and T32DC009401. The authors thank Drs. Seth Dailey, Charles Ford, and Timothy McCulloch for assistance with data collection, Dr. Nathan Welham for critical feedback on study design, and Dane County Youth Apprentice Program students April Barr and Sarah Wang for technical assistance. 


\section{References}

1. Rossi-and-Silva RC, Olegario JG, Correa RR, et al. Morphological characterization of the false vocal cords as larynx-associated lymphoid tissue. Pathology, research and practice. 2009; 205(1): 21-25.

2. Kutta H, Steven P, Kohla G, Tillmann B, Paulsen F. The human false vocal folds -- an analysis of antimicrobial defense mechanisms. Anat Embryol (Berl). 2002; 205(4):315-323. [PubMed: 12136262]

3. Kracke A, Hiller AS, Tschernig T, et al. Larynx-associated lymphoid tissue (LALT) in young children. The Anatomical record. 1997; 248(3):413-420. [PubMed: 9214559]

4. Belkaid Y, Piccirillo CA, Mendez S, Shevach EM, Sacks DL. CD4+CD25+ regulatory T cells control Leishmania major persistence and immunity. Nature. 2002; 420(6915):502-507. [PubMed: 12466842]

5. Weiner HL, da Cunha AP, Quintana F, Wu H. Oral tolerance. Immunological reviews. 2011; 241(1): 241-259. [PubMed: 21488901]

6. Turbachova I, Schwachula T, Vasconcelos I, et al. The cellular ratio of immune tolerance (immunoCRIT) is a definite marker for aggressiveness of solid tumors and may explain tumor dissemination patterns. Epigenetics : official journal of the DNA Methylation Society. 2013; 8(11): $1226-1235$.

7. Barth SD, Schulze JJ, Kühn T, et al. Treg-Mediated Immune Tolerance and the Risk of Solid Cancers: Findings From EPIC-Heidelberg. J Natl Cancer Inst. 2015; 107(11)

8. Jette ME, Gaumnitz EA, Birchall MA, Welham NV, Thibeault SL. Correlation between Reflux and multichannel intraluminal impedance $\mathrm{pH}$ monitoring in untreated volunteers. Laryngoscope. 2014

9. Kenford SL, Wetter DW, Welsch SK, Smith SS, Fiore MC, Baker TB. Progression of college-age cigarette samplers: what influences outcome. Addictive behaviors. 2005; 30(2):285-294. [PubMed: 15621399]

10. Husten CG. How should we define light or intermittent smoking? Does it matter? Nicotine \& tobacco research : official journal of the Society for Research on Nicotine and Tobacco. 2009; 11(2):111-121. [PubMed: 19246425]

11. Hanshew AS, Jette ME, Thibeault SL. Characterization and comparison of bacterial communities in benign vocal fold lesions. Microbiome. 2014; 2:43. [PubMed: 25671105]

12. Sehouli J, Loddenkemper C, Cornu T, et al. Epigenetic quantification of tumor-infiltrating Tlymphocytes. Epigenetics : official journal of the DNA Methylation Society. 2011; 6(2):236-246.

13. Team RC. R: a language and environment for statistical computing. Available at: http://www.rproject.org/. Available at, 2016

14. Barker E, Murison P, Macchiarini P, et al. Early immunological changes associated with laryngeal transplantation in a major histocompatibility complex-matched pig model. Clinical and experimental immunology. 2006; 146(3):503-508. [PubMed: 17100771]

15. Gong HL, Shi Y, Zhou L, et al. The Composition of Microbiome in Larynx and the Throat Biodiversity between Laryngeal Squamous Cell Carcinoma Patients and Control Population. PloS one. 2013; 8(6):e66476. [PubMed: 23824228]

16. Fontenot JD, Rasmussen JP, Williams LM, Dooley JL, Farr AG, Rudensky AY. Regulatory T cell lineage specification by the forkhead transcription factor foxp3. Immunity. 2005; 22(3):329-341. [PubMed: 15780990]

17. Herndler-Brandstetter D, Schwaiger S, Veel E, et al. CD25-expressing CD8+ T cells are potent memory cells in old age. J Immunol. 2005; 175(3):1566-1574. [PubMed: 16034095]

18. Amu S, Stromberg K, Bokarewa M, Tarkowski A, Brisslert M. CD25-expressing B-lymphocytes in rheumatic diseases. Scandinavian journal of immunology. 2007; 65(2):182-191. [PubMed: 17257224]

19. Hori S, Nomura T, Sakaguchi S. Control of regulatory T cell development by the transcription factor foxp3. Science. 2003; 299(5609):1057-1061. [PubMed: 12522256]

20. Hiller AS, Tschernig T, Kleemann WJ, Pabst R. Bronchus-associated lymphoid tissue (BALT) and larynx-associated lymphoid tissue (LALT) are found at different frequencies in children, 
adolescents and adults. Scandinavian journal of immunology. 1998; 47(2):159-162. [PubMed: 9496692]

21. Hiller AS, Kracke A, Tschernig T, et al. Comparison of the immunohistology of mucosa-associated lymphoid tissue in the larynx and lungs in cases of sudden infant death and controls. International journal of legal medicine. 1997; 110(6):316-322. [PubMed: 9387014]

22. Rees LE, Ayoub O, Haverson K, Birchall MA, Bailey M. Differential major histocompatibility complex class II locus expression on human laryngeal epithelium. Clinical and experimental immunology. 2003; 134(3):497-502. [PubMed: 14632757]

23. Gorti GK, Birchall MA, Haverson K, Macchiarini P, Bailey M. A preclinical model for laryngeal transplantation: anatomy and mucosal immunology of the porcine larynx. Transplantation. 1999; 68(11):1638-1642. [PubMed: 10609939]

24. Jecker P, Ptok M, Pabst R, Westermann J. Age dependency of the composition of immunocompetent cells and the expression of adhesion molecules in rat laryngeal mucosa. Laryngoscope. 1996; 106(6):733-738. [PubMed: 8656959]

25. Dietrich C, Jecker P, Tschernig T, Mann WJ. Presence of dendritic cells, T lymphocytes, macrophages, B lymphocytes and glandular tissue in the human fetal larynx. Acta Otolaryngol. 2004; 124(7):833-838. [PubMed: 15370569]

26. Barker E, Haverson K, Stokes CR, Birchall M, Bailey M. The larynx as an immunological organ: immunological architecture in the pig as a large animal model. Clinical and experimental immunology. 2006; 143(1):6-14. [PubMed: 16367928]

27. Kuss I, Hathaway B, Ferris RL, Gooding W, Whiteside TL. Decreased absolute counts of T lymphocyte subsets and their relation to disease in squamous cell carcinoma of the head and neck. Clinical cancer research : an official journal of the American Association for Cancer Research. 2004; 10(11):3755-3762. [PubMed: 15173082]

28. Geng Y, Savage SM, Razani-Boroujerdi S, Sopori ML. Effects of nicotine on the immune response. II. Chronic nicotine treatment induces T cell anergy. J Immunol. 1996; 156(7):2384-2390. [PubMed: 8786295]

29. Kalra R, Singh SP, Savage SM, Finch GL, Sopori ML. Effects of cigarette smoke on immune response: chronic exposure to cigarette smoke impairs antigen-mediated signaling in T cells and depletes IP3-sensitive Ca(2+) stores. J Pharmacol Exp Ther. 2000; 293(1):166-171. [PubMed: 10734166]

30. Rees LE, Jones PH, Ayoub O, et al. Smoking influences the immunological architecture of the human larynx. Clin Immunol. 2006; 118(2-3):342-347. [PubMed: 16386959]

31. Van de Louw A, Jean D, Frisdal E, et al. Neutrophil proteinases in hydrochloric acid- and endotoxin-induced acute lung injury: evaluation of interstitial protease activity by in situ zymography. Laboratory investigation; a journal of technical methods and pathology. 2002; 82(2): 133-145. [PubMed: 11850527]

32. Rabinovici R, Vernick J, Hillegas L, Neville LF. Hypertonic saline treatment of acid aspirationinduced lung injury. J Surg Res. 1996; 60(1):176-180. [PubMed: 8592411]

33. Rees LE, Pazmany L, Gutowska-Owsiak D, et al. The mucosal immune response to laryngopharyngeal reflux. American journal of respiratory and critical care medicine. 2008; 177(11):1187-1193. [PubMed: 18323539]

34. Pesenacker AM, Bending D, Ursu S, Wu Q, Nistala K, Wedderburn LR. CD161 defines the subset of FoxP3+ T cells capable of producing proinflammatory cytokines. Blood. 2013; 121(14):26472658. [PubMed: 23355538]

35. van der Weerd K, Dik WA, Schrijver B, et al. Morbidly obese human subjects have increased peripheral blood CD4+ T cells with skewing toward a Treg- and Th2-dominated phenotype. Diabetes. 2012; 61(2):401-408. [PubMed: 22228716] 
T Regulatory Cells

T Effector Cells

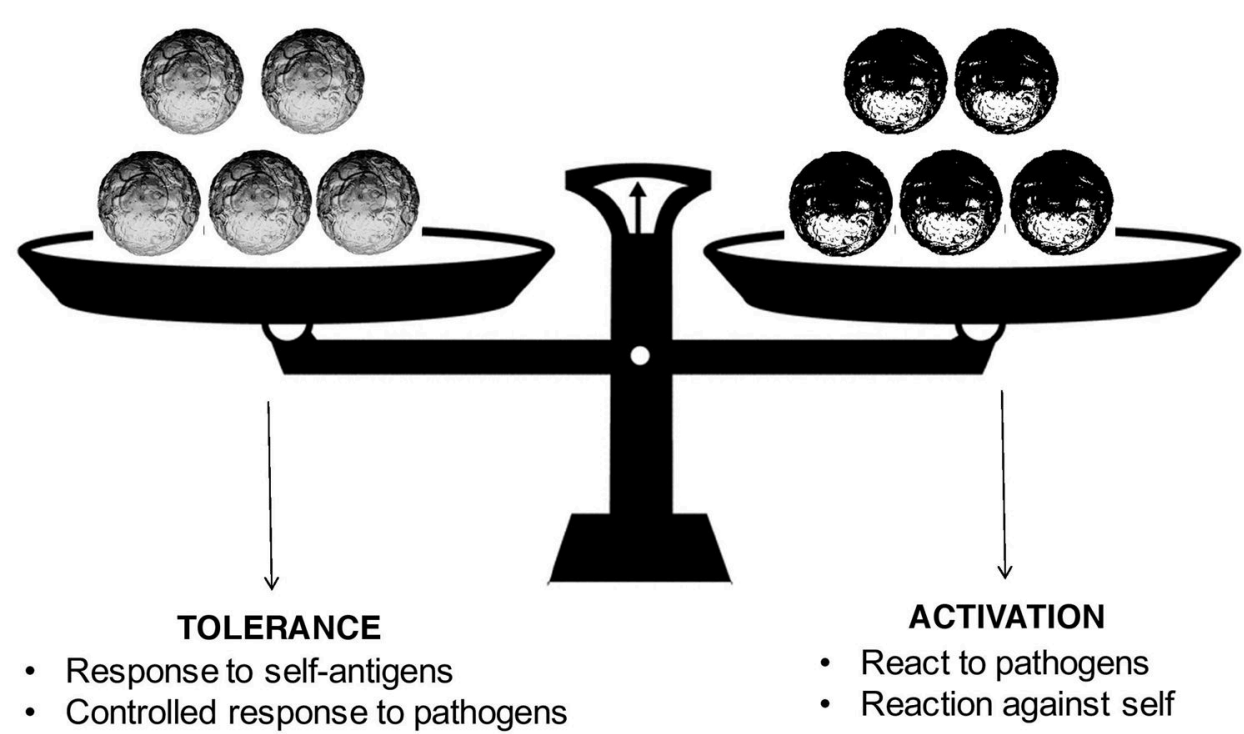

Figure 1.

A balance of $\mathrm{T}$ regulatory and $\mathrm{T}$ effector cells is necessary for an efficient immune response. 


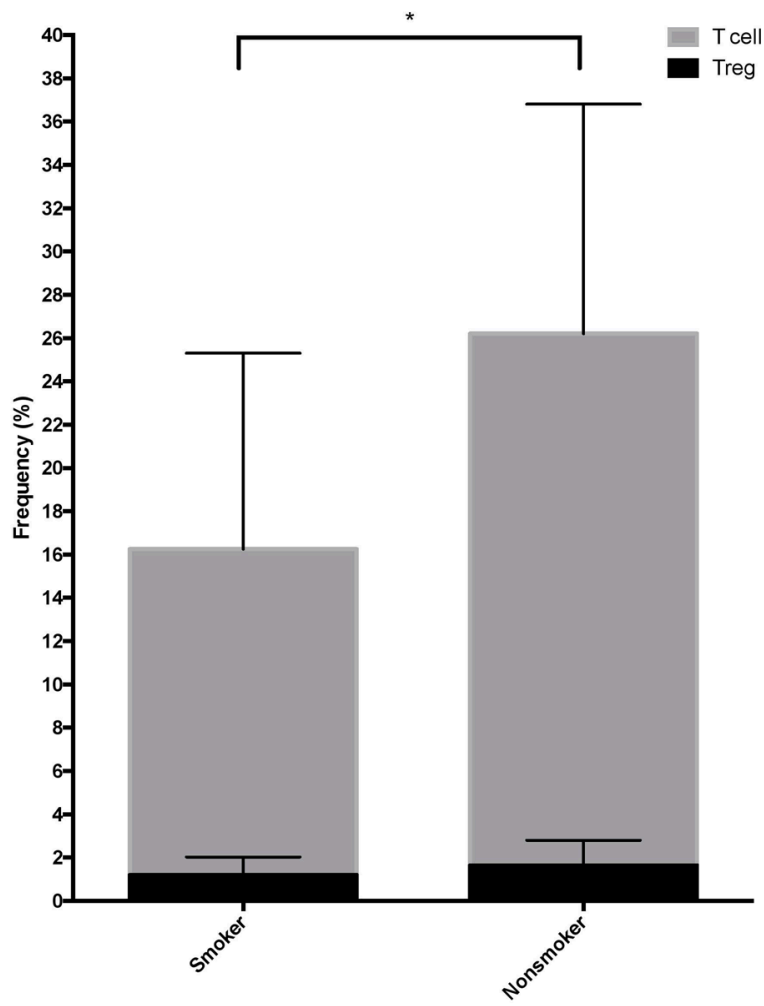

Figure 2.

Differences in $\mathrm{T}$ regulatory cell and total $\mathrm{T}$ cell frequency between smokers and nonsmokers with total $\mathrm{T}$ cell frequency decreased in smokers $(\mathrm{p}=0.02)$. Error bars show standard deviation. 


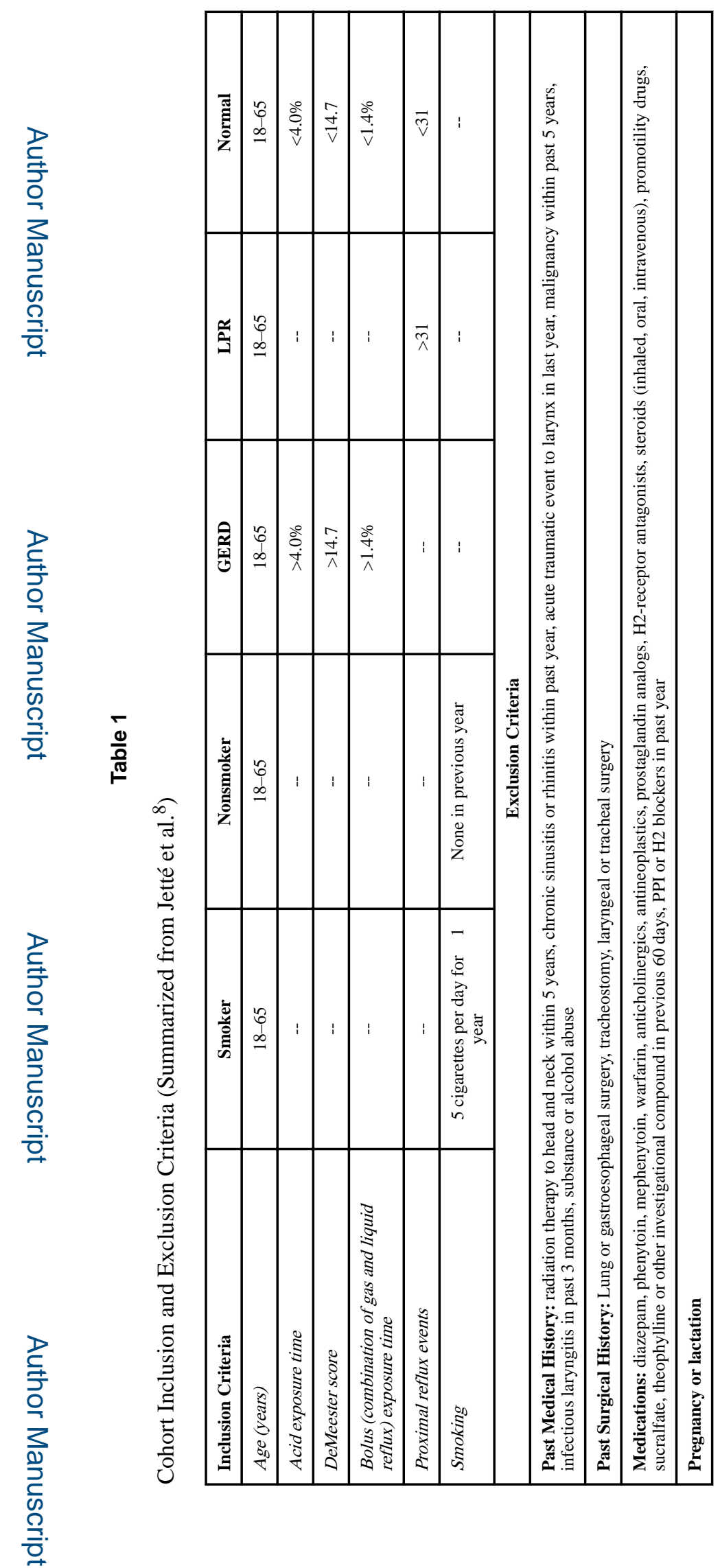

Laryngoscope. Author manuscript; available in PMC 2018 April 01. 


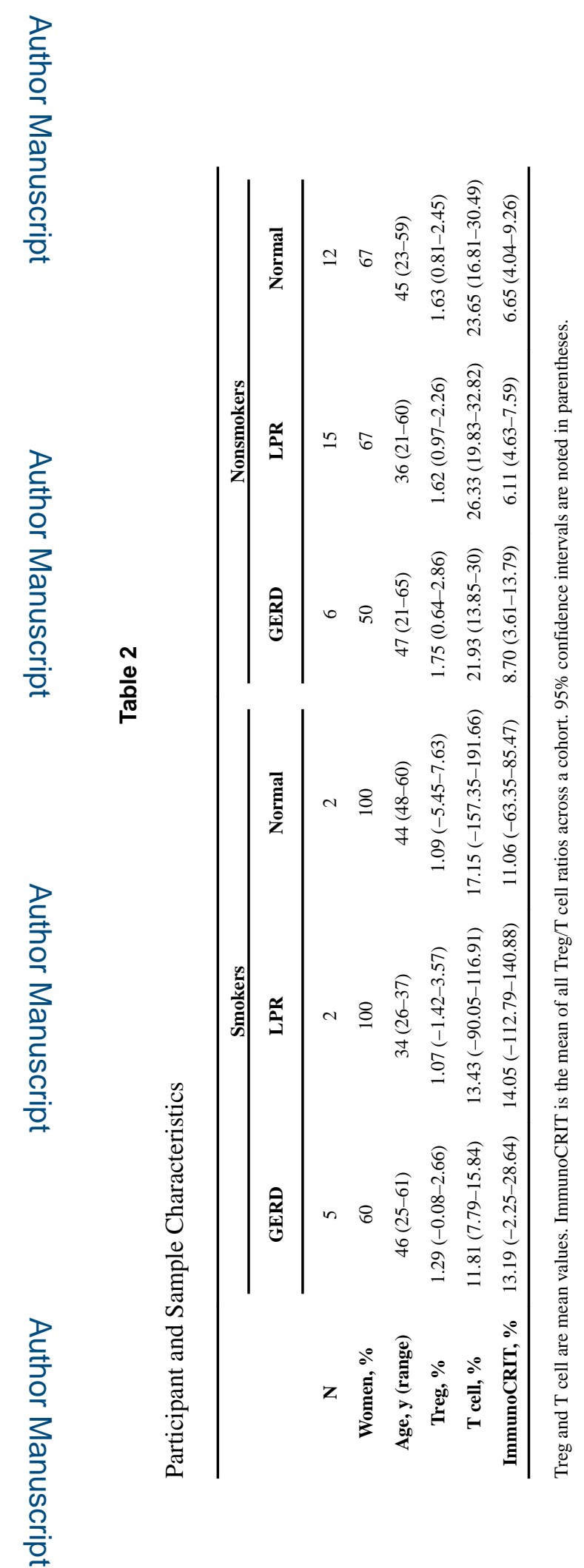



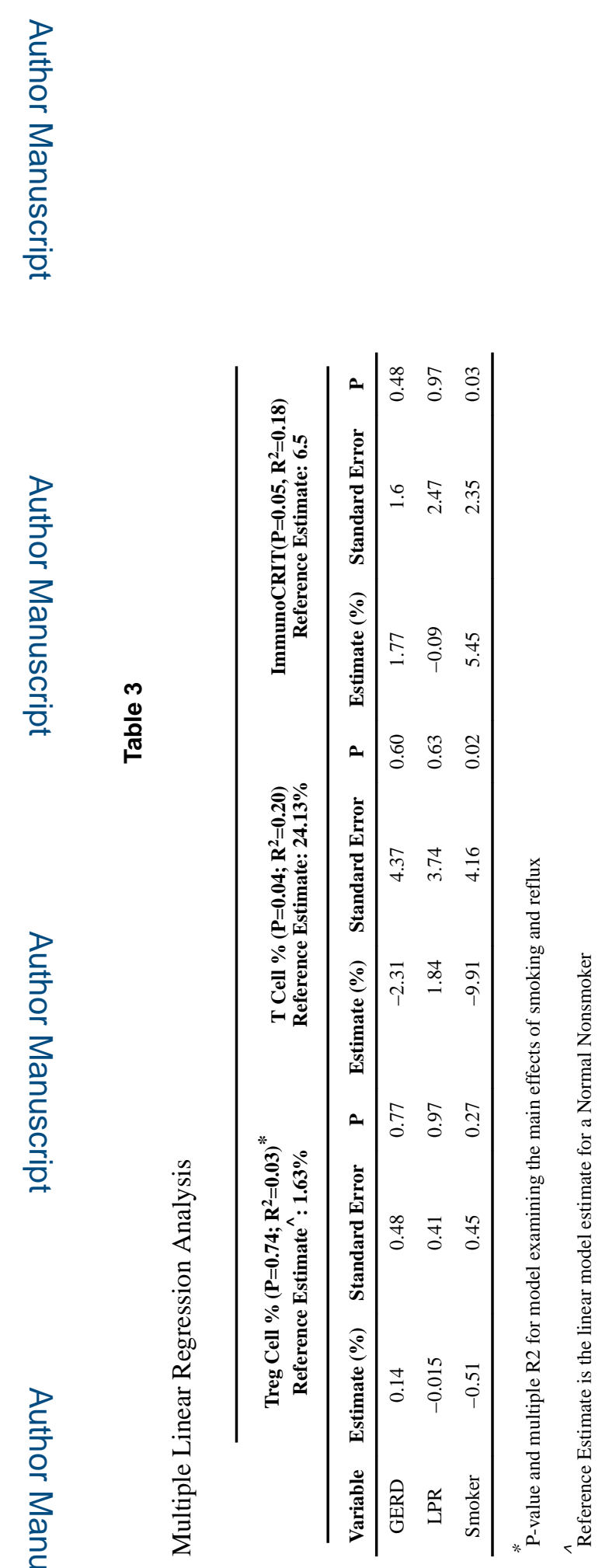